\title{
Communication breakdown: a cobertura do show de Robert Plant no festival Lollapalooza à luz do fait divers'
}

\section{Communication breakdown: the coverage of the Robert Plant concert at Lollapalooza festival in the light of fait divers}

Fábio Cruz

Pós-doutor em Direitos Humanos, Mídia e Movimentos sociais (Universidade Pablo de Olavide - Sevilha/Espanha). Doutor em Cultura Midiática e Tecnologias do Imaginário (PUCRS). Professor do curso de graduação em Jornalismo da Universidade Federal de Pelotas (UFPel). $<$ fabiosouzadacruz@gmail.com>

\section{Guilherme Oliveira Curi}

Mestre em Sociologia pela University College Dublin. Doutorando do Programa de Pós-Graduação em Comunicação da Universidade Federal do Rio de Janeiro (UFRJ) e pesquisador do Programa Nacional de Apoio à Pesquisa da Fundação Biblioteca Nacional. Integrante do Grupo de Pesquisa Diaspotics.

<curi.guilherme@gmail.com>

\section{RESUMO}

Com base em duas matérias publicadas no Portal Terra e no site do G1, propomos, neste artigo, a execução de um estudo da estrutura de linguagem do referido corpus analítico sobre o show do cantor inglês Robert Plant e sua banda Sensational Space Shifters no festival Lollapalooza, São Paulo, em março de 2015. Para tanto, adotamos como norte teórico os pressupostos da semiologia, de Barthes (1971), fixada na produção de sentido, em nível verbal, através do tipo de informação. A investigação conta com as noções de fait divers e será conduzida pelo método estruturalista.

\begin{abstract}
Based on two articles published at the websites Portal Terra and G1, we propose a structural language study of the analytical corpus of the British singer Robert Plant's concert with his "Sensational Space Shifters" band that happened at Lollapalooza Festival, São Paulo on March 2015. Therefore, we adopt as theoretical approach the Roland Barthes (1971) assumptions of semiotics, set in the production of meaning in the verbal level through the type of information. The research is also based on the notions of fait divers' concept and will be conducted by the structuralist method.
\end{abstract}

Keywords: Rock. Fait Divers. Opinion Journalism.

\section{Adentrando o palco}

O fait divers consiste na informação sensacionalista, que independe do estilo jornalístico. Portanto, é uma possibilidade bastante explorada pela mídia. Essa categoria tem um propósito único: priorizar a superficialidade com vistas a atingir o emocional das pessoas. No jornalismo opinativo, através da resenha

1 Este artigo contou com a colaboração de Natália Redü - Estudante de graduação do $77^{\circ}$ semestre do Curso de Jornalismo da Universidade Federal de Pelotas (UFPel). Bolsista PBIC/CNPq do projeto de pesquisa "Cultura da Mídia, Rock e Recepção". E-mail: < nataliaredu@gmail.com>. 
crítica de um espetáculo musical, por exemplo, um dos nossos focos de estudo aqui e que abordaremos no primeiro momento deste trabalho, o fait divers igualmente pode marcar presença.

Sendo assim, o que proporemos neste artigo é uma análise da cobertura do show do cantor inglês Robert Plant e sua banda Sensational Space Shifters no festival Lollapalooza, em São Paulo, no dia 28 março de 2015. De posse de um corpus composto por duas matérias publicadas no Portal Terra e no site do G1, pretendemos estudar a estrutura de linguagem dessas produções midiáticas. Para tanto, lançaremos mão do cabedal teórico do semiólogo Barthes (1971), que considera a produção de sentido, em nível verbal, através do tipo de informação. Neste sentido, laboraremos as noções da categoria fait divers, norteados pelo método estruturalista.

\section{Dos gêneros jornalísticos à resenha crítica}

O jornalismo é um campo de atuação muito vasto. Possui diversas áreas e subdivisões. Numa tentativa de facilitar os estudos e o ensino, doutrinadores e pensadores buscaram enumerar esses segmentos. Para tanto, foi feita a divisão do jornalismo em gêneros, considerando o veículo em que a notícia é inserida, o formato em que o texto é redigido, o assunto etc. Assim, delinearam-se os gêneros jornalismo opinativo, informativo, entre outros. No entanto, até hoje não chegamos a um consenso. $O$ que é unânime, como bem aponta Medina (2001) é que:

Realizar uma classificação universal dos mesmos é praticamente uma tarefa impossível, visto que estão sempre em transformação. “(...) Gêneros aparecem, crescem, mudam e desaparecem conforme o desenvolvimento tecnológico e cultural de cada nação e de cada empresa jornalística". (Medina, 2001, p. 45).

No Brasil, estudiosos clássicos da área como Beltrão e Marques de Melo classificam o jornalismo em gênero informativo e opinativo, com subdivisões. Beltrão ainda acrescenta o gênero jornalismo interpretativo, que seria a reportagem em profundidade (Costa, 2007). Nesta, "o tratamento é centrado no jornal e não é exaustivo quanto a estes outros tipos de prática jornalística" (Bonini, 2003, p.212).

Para Medina (2001, p. 48), "o gênero base é a notícia (relato puro dos acontecimentos)". Neste contexto, apesar das divergências na classificação dos gêneros, é indiscutível a presença da categoria jornalismo opinativo. Historicamente, foi esta que deu impulso ao jornalismo em sentido amplo. Os primeiros jornais tiveram grande influência da área da literatura, eis que escritos e idealizados por escritores. 
Entre os séculos XV e XVI, “(...) O jornalismo praticado era eminentemente opinativo, sendo que o informativo começou a delinear-se apenas após a Segunda Guerra Mundial, a partir dos Estados Unidos da América". (Martins, 2009, p. 493).

Foi neste período que com o bom êxito do jornalismo interpretativo nascente, os dirigentes de jornais observaram que tinham em mãos um negócio de futuro. Assim, os jornais foram se profissionalizando e se organizando em empresas bem estruturadas. Cada gênero passou a ter sua valorização específica. A notícia ganhou formato de indagação imparcial sobre os fatos, condensando no lead tudo o que era preciso para prender a atenção do leitor interessado na informação (Campo, 2001).

E mais adiante, Campo (2001) pontua que o jornalismo opinativo ganhou espaço próprio, tais como os editoriais e as colunas de opinião assinadas. Com isso, as empresas designaram os seus repórteres mais respeitados justamente para esta tarefa: redigir matérias opinativas e, por consequência, ter um texto com maior poder de influência e persuasão frente aos seus leitores.

Assim é possível afirmarmos que o jornalismo opinativo é um ramo do jornalismo especializado. Isso porque quando um crítico discorre sobre uma peça teatral, seu foco principal deve ser o teatro, não o espetáculo ou determinado ator. (Lage, 2001). Martins (2009) ainda lembra que quando o escritor da matéria faz uma análise de algum acontecimento, explicando e interpretando os fatos, destacando o que entende ser correto e em que pontos ele discorda, está exarando uma opinião de caráter eminentemente crítico.

$\mathrm{E}$, quando se trata de emitir opinião acerca de filmes, livros, espetáculos teatrais e/ou musicais, ainda estaria inserido no contexto do jornalismo cultural. Nesta linha de pensamento, Kindermann (2003, p. 357) lembra que "a análise de um gênero do jornal se faz em comparação com os demais gêneros, pois eles constantemente se mesclam".

Corrobora com esse entendimento a lição de Martins (2009), a saber:

Essas divisões, entretanto, podem não se apresentar tão demarcadas, caso se considere que tanto o jornalismo interpretativo quanto o diversional podem mesclar-se também com o jornalismo informativo e o opinativo, como no caso do fait divers que, informando fatos e acontecimentos que causam sensação, entretém a comunidade, dentro de uma necessidade social. (Martins, 2009).

A resenha crítica, por sua vez, consiste na análise, por um jornalista e/ ou um profissional especializado, a respeito de determinado assunto. Pode ser um filme, um livro, um espetáculo. A resenha deve conter um breve resumo do item e informações técnicas sobre o mesmo. Após, o resenhista tece seus 
comentários, positivos ou negativos. É a apresentação de uma obra ao leitor e uma forma de convencê-lo (ou não) a adquirir o produto cultural.

Assim, na resenha crítica, o destaque vai para a opinião nela manifestada, embora esta também contenha elementos de caráter informativo. Neste contexto, Campo (2001) aduz que o objetivo primordial do jornalismo opinativo é dar à notícia maior detalhamento, esmiuçar os fatos e facilitar o entendimento do leitor. Por isso que, não raro, especialistas são chamados para esta tarefa. No entanto, sempre devemos ter o cuidado para não influir e sugestionar a opinião do leitor sob pena de estarmos praticando um jornalismo enganoso. Martins (2009) corrobora com este pensamento ao lembrar que na atualidade, o jornalismo opera por meio da difusão, da periodicidade e da universalidade, atendendo a questões como o acesso às informações, e o emprego de meios como o rádio, a televisão, o texto impresso e a internet, possibilitando à comunidade o conhecimento dos fatos, para que possa se informar, orientar, formar uma opinião ou posicionar-se em relação aos acontecimentos (Martins, 2009).

Cumpre frisar, por fim, que as notícias selecionadas para análise são fruto do jornalismo online. E para este formato de jornalismo também se aplicam as características do gênero anteriormente abordadas. Isto ocorre porque o webjornalismo teve origem com o jornalismo impresso.

Com o surgimento da rede mundial de computadores, conhecida pela sigla "www", os noticiosos impressos, aos poucos, foram migrando para o mundo virtual. Num primeiro momento, as reportagens eram cópias fidedignas do que havia sido divulgado no veículo tradicional. Com o passar do tempo, são criados conteúdos próprios para internet e são inseridos outros tipos de mídia para complementar a escrita: vídeos, fotos, hiperlinks. Com a popularização da internet, as empresas de notícias se empenham na manutenção e desenvolvimento do jornalismo digital, surgindo portais de informação desvinculados dos meios impressos e, por óbvio, com conteúdo produzido exclusivamente para este meio (Carvalho; Gurgel, 2010). Bertocchi (2010, p.1296) explica que "o (web)jornalismo nasce vinculado ao meio papel e é no jornalismo impresso que existem as referências teóricas e práticas mais consolidadas".

Nesse diapasão é que as notícias selecionadas serão analisadas: se respeitam o que determinamos por jornalismo opinativo e resenha crítica ou se, ao contrário, são opiniões desprovidas de caráter técnico, parciais, que já impõem ao leitor uma visão positiva ou negativa do objeto analisado. Além disso, conforme iremos expor nos pressupostos teórico-metodológicos deste 
artigo, nosso próximo tópico, aplicaremos também as noções do fait divers (Barthes, 1971).

\section{Referencial teórico}

O "casos do dia", mais conhecido por fait divers, consiste em uma das principais categorias de Barthes, voltada para os meios de comunicação social. Com uma abordagem estruturalista, ele Ihe deu conceito, tipologia e subtipologia. Assim, estabeleceu a sua teorização.

O fait divers é a informação sensacionalista, procedente de uma classificação do inclassificável. É uma "informação monstruosa, análoga a todos os fatos excepcionais ou insignificantes, em resumo, anônimos" (Barthes, 1971, p.263). Neste contexto, a palavra monstruosa significa grotesco, descomunal, insólito, hediondo e incrível. Especifica a essencialidade dessa categoria barthesiana.

Diariamente, vivenciamos uma magnífica exploração do fait divers na imprensa, quando esse é classificado como informação geral. Alguns exemplos desenvolvem-se durante vários dias, o que não quebra sua imanência constitutiva, porque implica, sempre, uma memória curta, efêmera.

Para Ramos (1999), as relações que dizem respeito ao fait divers expressam conflito, atingem a emoção do receptor, independentemente de seu estilo jornalístico; são constituídas pelo excepcional, pelo grotesco, que valorizam o espetacular, e podem ser reduzidas em dois tipos básicos: causalidade e coincidência. Ambos apresentam subtipologias respectivas, direcionadas para a compreensão da excepcionalidade, condição do estabelecimento da noção de conflito.

O fait divers de causalidade revela dois tipos: a causa perturbada, quando se desconhece ou não é possível precisar a causa e, ainda, quando uma pequena causa provoca um grande efeito; e a causa esperada, a partir da qual quando a causa é normal, a ênfase desloca-se para os dramatis personae (personagens dramáticos), como, por exemplo, crianças, mães e idosos (Barthes, 1971).

$\mathrm{Na}$ causa perturbada, ocorrem fatos excepcionais, espantosos, que implicam perturbação, conflito. Há um efeito (o conflito surge daí). No entanto, a causa é desconhecida, imprecisa ou, até mesmo, ilógica, sem sentido. Não obstante, uma pequena causa pode provocar um grande efeito. Há uma riqueza de desvios causais. Devido a certos estereótipos, esperamos uma causa e surge outra, mais pobre do que a esperada. Neste gênero de relação causal, há o espetáculo de uma decepção; paradoxalmente, quanto mais escondida, mais notada será essa causalidade. 
Barthes (1971) divide o fait divers de coincidência em dois tipos: de repetição - quando a informação repetida leva a imaginar causas desconhecidas, que ocorrem em circunstâncias diferentes - e de antítese, quando se aproximam dois termos qualitativamente distantes.

A antítese une dois termos opostos, como se nunca tivessem sido, estabelecendo a noção de conflito, disponibilizando a emocionalidade. Em cada termo, pertencendo a um percurso autônomo de significação, a relação de coincidência apresenta, como função paradoxal, fundir dois percursos diferentes em um percurso único (Ramos, 1999).

Utilizado constantemente pela mídia, o fait divers reflete o capitalismo contemporâneo que, através dos seus significados e métodos, fornece elementos que tendem a relegar os indivíduos à passividade e à manipulação ao mesmo tempo que obscurecem a natureza e os efeitos do poder vigente. Fomentando uma memória curta e efêmera, o fait divers reflete e reforça algumas das premissas da era globalizante: as informações devem ser líquidas e, ao mesmo tempo, devem atingir o emocional das pessoas (Cruz, 2012).

Possuindo um consumo imediato e provido de um caráter atemporal, o fait divers, em suas diferentes manifestações, é utilizado, na mídia, com diversas abordagens. Aparece no tratamento da realidade e da ficção, seja nas telenovelas, nos telejornais, nos talk shows, nos programas humorísticos, no noticiário da imprensa e na publicidade (Ramos, 1999).

Juntos, a mídia e o fait divers independem de estilo jornalístico e mostram, em vez de demonstrar, informar com veemência e aprofundamento, os fatos do dia, pois priorizam a superficialidade, com base no emocional.

\section{Metodologia}

A proposta desta pesquisa é de cunho teórico-prático, uma vez que procuraremos aliar o cabedal teórico ao processo de análise do corpus composto pelas matérias veiculadas no Portal Terra e no site do G1, da TV Globo, sobre o show de Robert Plant e sua banda, a Sensational Space Shifters, no dia 28 de março de 2015, no festival Lollapalooza , em São Paulo, Brasil. Posteriormente, os dados obtidos (evidências) serão devidamente categorizados e analisados (atividade de agenciamento) para que, assim, possam ser encaminhadas as devidas conclusões. Investigaremos, portanto, o tipo de informação, fixada na produção de sentido, em nível verbal.

Demo (1992) afirma que, no horizonte epistemológico do estruturalismo, produzir conhecimento da realidade implica revelar os elementos constituintes, constantes supra-espaciais e supratemporais. E complementa afirmando que o seu objeto é a invariante, o imutável na dialética histórica. 
Segundo Demo (1992, p.172), o termo estrutura está relacionado ao essencial dos problemas; é o fundamento, a base. "Refere um todo, onde convivem partes convergentes e divergentes em uma relação dialética, delineada pelo movimento". Para Barthes (1971, p.299), a estrutura é peça essencial para o fait divers: "A estrutura é, pois, na verdade um simulacro do objeto, mas um simulacro dirigido, interessado, uma vez que o objeto imitado faz algo que permanecia invisível, ou se preferirmos, ininteligível no objeto natural".

Ramos (1999) afirma: "Na abordagem estruturalista, o mais importante não é o dito. As histórias, os protagonistas e as circunstâncias são significações variáveis no tempo e no espaço. São perecíveis". E continua: "O que importa é a estrutura, a forma de dizer, o significante invariante, que tem permanência perante quaisquer possibilidades de mutação". Considerando isso, esse autor alerta para o fato de que, em qualquer tipo de fait divers, é possível que ocorra a interação de Causalidade e Coincidência.

De acordo com os pressupostos de Barthes (s.d.), a semiologia é, simultaneamente, negativa e ativa. É negativa, pois nega que o signo tem caráter absoluto, uma verdade absoluta. Constitui-se em algo relativo, porque é produzido na sociedade, é histórico. Não é reconhecida somente pela escrita, mas, também, pela linguagem, pela fala. É ativa, porque é feita da vida, preocupa-se com o cotidiano, com textos do imaginário, como, por exemplo, fotos, reportagens.

Conforme sustenta Barthes (1997), a comunicação necessitava de uma perspectiva transdisciplinar. Para tanto, articulou o linguístico com o translinguístico, adotando, assim, uma postura dialética. Assim, rompeu com o estruturalismo restrito pelo funcionalismo. Além do aspecto social, histórico, Barthes adota a fala (translinguístico), além do estudo da língua (além do texto, o contexto).

Para Barthes (1997, p.106), o objetivo essencial da pesquisa semiológica é "descobrir o tempo próprio dos sistemas, a história das formas". Para ele, a forma é invariante e tem por objetivo buscar as "singularidades históricas das estruturas invariantes" (Ramos, 1999). Escolhendo a pesquisa semiológica qualitativa à quantitativa, acrescenta que "o objetivo é aqui distinguir unidades e não contá-las" (Barthes, 1979, p. 11).

No que tange à investigação da linguagem das matérias selecionadas, a pesquisa semiológica é pertinente. Segundo Barthes, o princípio de pertinência constitui-se em um fator importante no estudo semiológico:

Para compreender essa pesquisa, é necessário aceitar, francamente, desde o início (e, principalmente, no início), um princípio limitativo. Esse princípio, mais uma vez oriundo da linguística, é o princípio de pertinência: decida-se o 
pesquisador a descrever os fatos, reunidos a partir de um só ponto de vista e, por conseguinte, a reter, na massa heterogênea desses fatos, só os traços que interessam a esse ponto de vista, com a exclusão de todos os outros (esses traços são chamados pertinentes). (Barthes,1997,p.103).

Dessa forma, a necessidade de demarcarmos o objeto é necessária, o que é contemplado pelo princípio de pertinência, que proporciona ao pesquisador a particularização de acordo com seus interesses de estudo.

\section{Analisando o caso}

A obtenção e escolha do material a ser analisado no presente artigo foram feitos da seguinte forma: no dia seguinte ao show buscamos, nos sites de notícia e entretenimento, as matérias que abordavam a apresentação do cantor Robert Plant e banda no festival Lollapalooza. Ao todo, identificamos 13. Deste total, selecionamos duas reportagens: uma publicada no Portal Terra e outra no site do G1. A opção por essas, em especial, se deu pelo fato de serem antagônicas.

\section{O Vocalista}

Nascido em 20 de agosto de 1948, em West Bromwich, Inglaterra (Rees, 2014), Robert Anthony Plant começou a integrar bandas de rock na adolescência. Entre estas estava The Crawling King Snakes, na qual o vocalista conheceu o baterista John Bonham (Williamson, 2011). Este, em pouco tempo, viria a tornarse seu grande amigo.

Após fracassar em alguns singles (canção viável comercialmente e lançada individualmente pelo artista e pela gravadora) como artista solo, Plant recebe um convite do guitarrista londrino Jimmy Page para integrar um novo projeto juntamente com o baixista e tecladista John Paul Jones. O cantor recomenda John Bonham para a bateria e assim, em 1968, é formado o Led Zeppelin.

Durante os seus doze anos de existência, o quarteto vendeu milhões de discos ao redor do mundo, quebrou recordes de público em seus shows e estabeleceu-se como a principal banda da década de 1970. Com o fim do Led Zeppelin, Robert Plant partiu para uma carreira solo que dura até hoje. Durante a apresentação no festival Lollapalooza, o cantor promovia o seu novo disco, Lullaby and... The Ceaseless Roar, lançado em setembro de 2014.

\section{O Festival}

Criado em 1991 pelo vocalista do grupo norte-americano Jane's Addiction, Perry Farrel, o Lollapalooza já teve em suas fileiras nomes consagrados do cenário musical como Metallica, Red Hot Chili Peppers, Pearl Jam, The Cure e Soundgarden. Gestado apenas com o intuito de ser parte da turnê de despedida 
da banda do cantor, o festival durou até 1997, regressando em 2003 para uma nova bateria de shows do Jane's Addiction em 30 cidades.

No ano seguinte, a turnê foi cancelada após duas apresentações em cidades distintas devido à baixa venda de ingressos. Após o fato, no entanto, “Perry Farrel consolidou uma parceria com Capital Sports \& Entertainment (atual C3 Presents), para produzir o Lollapalooza. Junto à William Morris Agency e Charles Attal Presents, o grupo deu nova vida ao Lollapalooza. Desde 2012 no Brasil, a edição de 2015, realizada no Autódromo de Interlagos, em São Paulo, marcou a quarta passagem do festival pelo país.

\section{Descrevendo as matérias}

A análise do Portal Terra é assinada por Migueres (2015) e consiste numa crítica positiva. A resenhista começa enaltecendo a performance do músico, destacando que, apesar da idade avançada e do físico um pouco fora de forma, sua voz permanece impecável e encantando gerações.

Quanto ao setlist (repertório das músicas executadas na apresentação), esclarece que se trata de uma mescla de músicas da carreira solo de Plant com algumas do Led Zeppelin. Ainda informa que uma das canções, embora mais conhecida na voz do referido grupo, é de autoria de outro músico. Falando em banda, ao analisar a Sensational Space Shifters, a repórter segue com os elogios. Inclusive, pontua que os instrumentistas foram igualmente responsáveis, tanto quanto o vocalista, pelo sucesso da apresentação.

Por fim, a jornalista destaca que os novos arranjos em algumas canções, em especial na música Rock and Roll , foram os momentos ápices do espetáculo. Conclui que a plateia tenha ficado plenamente satisfeita com a apresentação.

A reportagem do site G1, assinada por Shin Oliva Suzuki (2015), por sua vez, tem caráter de crítica negativa. A matéria começa com uma imagem do cantor ao lado de breves informações. Dentre estas se destaca a que discorre sobre a música "Rock and Roll", salientando que a canção, que deveria ser um dos momentos altos do espetáculo, teria sido uma frustração aos fãs, principalmente em virtude do arranjo diferenciado.

O repórter começa o texto destacando a simpatia de Plant com a plateia, a qual presume ter ficado satisfeita com a apresentação de sete clássicos da banda Led Zeppelin. Em seguida, faz ligeira crítica à voz do músico, dizendo que "ele parece aceitar a limitação da idade e não arrisca as notas mais altas em músicas como a zeppeliana What is and what should never be".

Quando se refere aos novos arranjos em determinadas canções, Suzuki entende que isso deixou o show "morno", não agradando o público. O jornalista 
também classifica a banda que acompanha Plant como competente, mas que, no entanto, não foi capaz de conferir um "bom acabamento" às músicas.

Para concluir a reportagem, Suzuki retoma a crítica estampada logo no começo da matéria, alertando que o arranjo diferenciado na faixa Rock and Roll tirou "a força do bis". E finaliza determinando que "Plant pode ser admirável por se arriscar em ritmos diferentes, mas a mágica só acontece de fato quando ele faz o que sabe fazer", ou seja, para o jornalista, o show deixou a desejar.

\section{O espetáculo, as críticas e o fait divers}

Na construção das notícias jornalísticas, o primeiro parágrafo, conhecido como lead, deve responder algumas perguntas básicas: o quê, quem, quando, onde, como e por quê. Esta regra advém da ideia da pirâmide invertida, em que os fatos relatados são descritos em ordem decrescente de importância. $O$ objetivo é prender a atenção do leitor desde o começo.

Na reportagem produzida pelo portal Terra - "Robert Plant arrepia fãs do Zeppelin e mostra vigor no Lolla" -, o parágrafo inicial contém as respostas para essas perguntas. Porém, há lacunas, explicamos.

A jornalista que escreveu o texto pressupõe que o leitor já tenha conhecimento sobre o que seja o Lollapalooza bem como da relação existente entre "Robert Plant" e "fãs de Led Zeppelin". Tais informações são apresentadas ao longo do texto, somente. Além disso, a repórter não elucida a razão do setlist enxuto, a qual se explica em virtude da apresentação estar ocorrendo em um festival, no qual vários artistas participam e o espaço destinado a cada um é reduzido.

Aplicando as noções de fait divers nesta reportagem, é possível observarmos muitas antíteses no texto. Verificamos a primeira delas quando a escritora, ao mesmo tempo em que destaca o vigor do artista, refere-se a ele como um veterano. Mais adiante, ela se reporta a Plant como uma referência em termos de voz - "um dos maiores vocalistas de todos os tempos", "cara que inspira gerações de vocalistas há mais de 40 anos", "uma das vozes mais marcantes do rock" - e também como lenda.

Há, ainda, uma antítese equivocada no seguinte trecho: "Plant começou com a sua tímida aparição no palco, [...\} para mandar a primeira cacetada, Babe I'm Gonna Leave You (...)". Ocorre que quem conhece a música referida sabe que sua introdução é lenta, devagar, exatamente como na apresentação. A aparição do vocalista, portanto, não foi comedida. Não havia sentido em subir ao palco de modo frenético se o ritmo da música não era tão agitado. $O$ cantor, assim, apenas entrou em cena como qualquer outro músico. 
Constatamos o fait divers de coincidência através do subtipo repetição quando a jornalista, por três vezes, refere-se a Plant como "veterano", o que também torna o vocalista um personagem dramático acusando o fait divers de causalidade a partir da causa esperada. Outrossim, é possível inferirmos o fait divers de causalidade com o subtipo causa perturbada no momento em que a repórter diz que "a cada agudo rouco de Plant, o público respondia com delírio". Isso porque não é explicado ao leitor - causa desconhecida - porque uma voz rouca deixava os fãs em êxtase. Deste modo, cada receptor poderá ter uma conclusão diversa. Igualmente percebemos a causa perturbada quando Migueres fala em "público nostálgico", eis que não explica que a música executada - Ramble on - faz parte do catálogo do Led Zeppelin, justificando, assim, o saudosismo.

Além disso, a reportagem lança mão novamente da repetição também quando apresenta Plant sempre através da reiterada referência ao Led Zeppelin, do qual o artista foi cantor e atingiu a fama. Ocorre que a carreira solo do músico já é maior que o tempo de existência do dito grupo musical. Logo, não há nada que justifique essa permanente conexão. Inclusive, em determinado trecho do artigo, notamos que a jornalista ignora a trajetória pós-Zeppelin do vocalista ao mencionar que "Robert Plant fez a alegria dos fãs do Led Zeppelin", ou seja, excluiu deste grupo todos os fãs do projeto próprio, que até mesmo podem não conhecer e/ou não apreciar a banda inglesa.

Não obstante, há uma referência errada na legenda das imagens (a qual é idêntica em todas as fotos) que ilustram a matéria. De acordo com o texto explicativo, Plant seria o líder do Led Zeppelin, o que expõe de novo o fait divers de causalidade através do subtipo antítese. Porém, uma pessoa que, de fato, conhece a história da banda ou ao menos estudou a respeito para elaborar a resenha, saberia que o mentor do grupo era Jimmy Page.

O texto refere-se às canções "Arbaden" e "Turn It Up" como hits solos. Contudo, tais músicas não tiveram tanto sucesso comercial para serem encaradas dessa forma. Importante mencionarmos, ainda, que "Arbaden" não foi tocada na íntegra, apenas um trecho foi inserido no curso da música "Black Dog", ao contrário do que sugere a jornalista. Constatamos outro equívoco no instante em que Migueres sustenta que a canção "Rainbow" foi tocada após "The Lemon Song". Na realidade, "Rainbow" foi a segunda música do show e "Little Maggie" o número subsequente a "The Lemon Song".

Assim, de todo o exposto, fica evidente que a jornalista responsável pela elaboração da reportagem ora analisada não se preparou adequadamente para redigir o texto. Ainda que o artista ou o gênero musical não seja do gosto do profissional, é indispensável que este estude sobre os temas que irá discorrer. 
Além disso, o deslize apontado no tocante à ordem das músicas deixa notória a falta de atenção da repórter, que sequer conferiu as informações.

A pressa não é argumento para justificar tais desacertos. Da forma como o texto foi redigido, a impressão que a jornalista pode passar ao leitor que realmente conhece Robert Plant e o Led Zeppelin é a de que foi realizada uma pesquisa "de última hora". Nestas situações em que não há nenhum "furo" a ser informado, é preferível demorar um pouco mais para divulgar a notícia, mas fazer um relato com informações corretas e quiçá com maior profundidade.

Com relação à matéria do G1, intitulada "Robert Plant acerta na performance e no blues e escorrega no'toque étnico'", o que vemos são repetidos apontamentos voltados quase que exclusivamente para a fase Led Zeppelin do cantor - "Robert Plant conseguiu satisfazer o público que veio sedento para ter um verdadeiro Led Zeppelin no palco à sua frente. Foram sete clássicos da banda no show deste sábado (...)".

Mais enxuta que a reportagem anterior, novamente, aqui, percebemos o uso do fait divers, embora de forma mais comedida. Outra vez o rótulo de lenda do rock abrolha, o que acusa o fait divers de coincidência através da antítese. Este subtipo também aparece quando Plant é tido como um frontman "simpático e cortês" com o público presente no espetáculo, "conversando em português diversas vezes: um 'ê galera' aqui, um 'senhoras e senhores' acolá (...)".

Igualmente notamos a presença do fait divers de causalidade com a causa esperada quando a idade do vocalista vem à tona: "Robert Plant se movimentou bastante no palco para um frontman de 66 anos. A idade, como é natural, já não permite que Plant alcance seus agudos dos tempos mais famosos. Ele parece aceitar a limitação da idade e não arrisca as notas mais altas (...)".

Em que pesem as ligações estabelecidas e a questão da idade do vocalista, o que realmente perturba o jornalista são os cruzamentos de Plant com os sons do oriente, os quais não vingam e consequentemente promovem uma espécie de amornamento do show. Isso resulta, também, em um bis sem força com a zeppeliniana "Rock and Roll", "que foi tocada mais lenta e sem a famosa introdução de bateria". Ao contrário disso, segundo a reportagem, o cantor obtém destacado desempenho quando volta às suas raízes: "Bom mesmo é quando Plant e banda se dedicam ao blues que serviu de base para o Led Zeppelin, como em 'Spoonful', de Willie Dixon, e 'Fixin to die', de Bukka White".

Para finalizar, temos o habitual desdém para com a carreira solo de Plant junto à costumeira exaltação do seu passado: "Plant pode ser admirável por se arriscar em ritmos diferentes, mas a mágica só acontece de fato quando ele fazo que sabe fazer". Ao que parece, em ambas as reportagens, o legado zeppeliniano é o que realmente importa. 


\section{Acordes finais}

Como demonstramos, o fait divers é uma categoria onipresente nas produções midiáticas. De consumo instantâneo, ele é rico em promover desvios causais atingindo, assim, a emoção do sujeito receptor. Partindo disso, percebemos a sua utilização nas duas resenhas críticas escolhidas como corpus de análise.

Nesse sentido, identificamos todos os tipos e subtipos de fait divers no referido material. Servindo de modelo e inquestionável influência a gerações de vocalistas ao redor do mundo, o "veterano" Plant é, assim, considerado uma lenda por ambos os repórteres, caracterização esta que denota a antítese ao promover a fusão de percursos distintos.

Embora apareça mais na primeira crítica analisada, a questão da idade do músico ganha vigor na segunda reportagem. Aqui, o fait divers de causalidade, através da causa esperada, reina absoluto. A simples constatação de que um senhor de 66 anos movimentou-se muito no palco, mas, concomitantemente, também aceita as restrições do avançado tempo de vida ao não explorar mais os agudos do exitoso passado, pode ser digna de comover os leitores mais desavisados.

Todavia, se adjetivos e ligações de percursos diferentes em torno de um só ator, além da quase obrigatória alusão à idade de Plant possam ser considerados possibilidades inevitáveis, por outro lado, a insistência em falar sobre o passado do vocalista ofusca definitivamente os seus voos como artista solo.

Mesmo reconhecendo a inegável importância do Led Zeppelin, o constante atrelamento de uma nota só ao grupo britânico a partir do qual Plant se tornou um ícone impede a execução de novos acordes nas referidas produções midiáticas. Neste sentido, o uso do fait divers de coincidência a partir do subtipo repetição faz com que ambas não avancem, ficando presas ao passado do vocalista.

Essa constatação reforça a hipótese de desconhecimento da carreira pósZeppelin do cantor, que, repetimos, é mais longínqua que o período de existência da própria banda. Tal suposição adquire robustez quando nos deparamos com outro tipo de fait divers: a causa perturbada. No momento em que não há a devida contextualização a respeito da conexão entre Plant e o Led Zeppelin, algumas informações apresentadas, por vezes, podem parecer sem nexo.

Por menos prejudicial que possa aparentemente parecer, ambas as críticas musicais aqui estudadas demonstram o quanto a superficialidade jornalística se faz presente no cotidiano midiático brasileiro. Além disso, torna-se evidente, mesmo sem adentrarmos por escolha metodológica de análise, fatores como 
estereotipização e esvaziamento do signo (conceito muito caro aos estudos semiológicos barthesianos).

Exímias ferramentas da superficialidade, essas construções barthesianas se tornam ainda mais nocivas quando somadas a legítimas comprovações de desconhecimento. Prestando um desserviço ao leitor, as produções investigadas promovem uma pane na comunicação. E isso vale tanto para os fãs do Led Zeppelin quanto para os fãs da carreira solo de Robert Plant. Ou ambos.

\section{Referências}

BARTHES, Roland. Aula. São Paulo: Cultrix, 1997.

Sistema da moda. São Paulo: Nacional/USP, 1979.

Ensaios críticos. Lisboa: Edições 70, 1971.

BERTOCCHI, Daniela. Gêneros jornalísticos em espaços digitais. In: SOPCOM 2005, Aveiro, Portugal, Actas do $4^{\circ}$ Congresso da Associação Portuguesa de Ciências da Comunicação, Universidade de Aveiro, Portugal, 20 e 21 de Outubro, p. 1287-1299. Disponível em: <http://www.bocc.ubi.pt/pag/bertocchi-danielageneros-jornalisticos-espacos-digitais.pdf > . Acesso em: 27 abr. 2015.

BONINI, Adair. Os gêneros do jornal: o que aponta a literatura da área de comunicação no Brasil? In: Linguagem em (Dis)curso, Tubarão, v. 4, n. 1, p. 205-231, jul./dez. 2003. Disponível em: <https://www.portaldeperiodicos.unisul.br/ojs/index. php/Linguagem Discurso/article/view/263/277> . Acesso em: 6 abr. 2015.

CAMPO, Pedro Celso. Gênero Opinativo. In: Observatório de Imprensa OnLine, 2001. Disponível em: <www.observatoriodaimprensa.com.br/artigos/da010520026. htm>. Acesso em: 6 abr. 2015.

CARVALHO, Tatiane. E. M.; GURGEL, Eduardo Amaral. Gêneros jornalísticos no ciberespaço: estudo sobre os portais UOL e G1. Caxias do Sul: Intercom, 2010. Disponível em: <http://www.intercom.org.br/papers/nacionais/2010/resumos/ R5-0847-1.pdf>. Acesso em: 27 abr. 2015.

COSTA, Lailton Alves da. Jornalismo Brasileiro: a teoria e a prática dos gêneros jornalísticos em cinco jornais do país. In: XXX Congresso Brasileiro de Ciências da Comunicação, 2007. v. 1. Disponível em: <http://encipecom.metodista.br/ mediawiki/images/1/10/GT4- 17-Jornalismo brasileiro- Lailton.pdf>. Acesso em: 6 abr. 2015. 
CRUZ, Fábio Souza da. Os movimentos sociais e a mídia em tempos de globalização: um estudo das abordagens de jornais brasileiros e espanhóis sobre o MST e os direitos humanos. Disponível em: <http://revistaseletronicas.pucrs.br/ojs/ index.php/revistafamecos/article/view/12902/8607>. Acesso em: 4 maio 2015.

DEMO, Pedro. Metodologia científica em ciências sociais. São Paulo: Atlas, 1992.

KINDERMANN, Conceição. O estudo dos gêneros no jornal: o caso da reportagem. In: ENCONTRO DO CELSUL, 5., p. 352-359, 2003. Disponível em: <http://www. celsul.org.br/Encontros/05/pdf/047.pdf>. Acesso em: 6 abr. 2015.

LAGE, Nilson. A reportagem: teoria e técnica de entrevista e pesquisa jornalística. São Paulo: Record, 2001.

MARTINS, Maria Angélica Seabra Rodrigues. Discurso, ideologia e persuasão no jornalismo opinativo. In: Estudos Linguísticos, São Paulo, p. 493-507, set./ dez. 2009. Disponível em: <http://gel.locaweb.com.br/estudoslinguisticos/ volumes/38/EL V38N3 39.pdf>. Acesso em: 6 abr. 2015.

MEDINA, Jorge Lellis Bomfim. Gêneros Jornalísticos: repensando a questão. In: Revista Symposium, Ano 5, n 1, , p. 45-55, janeiro-junho 2001. Disponível em: < http:// www.maxwell.vrac.puc-rio.br/3196/3196.PDF>. Acesso em: 6 abr. 2015.

MIGUERES, Luisa. Portal de notícias Terra. Disponível em: <http://musica.terra.com. br/lollapalooza/robert-plant-arrepia-fas-do-zeppelin-e-mostra-vigor-no-lolla fc68f9005a26c410VgnVCM3000009af154d0RCRD.html>. Acesso em: 28 abr. 2015.

RAMOS, Roberto. Anotações de sala de aula. Porto Alegre: PUCRS, 1999.

REES, Paul. Robert Plant: uma vida. São Paulo: LeYa, 2014.

SUZUKI, Shin Oliva. Robert Plant acerta na performance e no blues e escorrega no toque étnico. In: Portal de notícias G1. Disponível em: <http://g1.globo.com/musica/ lollapalooza/2015/noticia/2015/03/robert-plant-acerta-na-performance-e-noblues-e-escorrega-no-toque-etnico.html>. Acesso em: 28 abr. 2015.

WILLIAMSON, Nigel. O guia do Led Zeppelin. São Paulo: Aleph, 2011.

Recebido em: 09/7/2015

Aceito em: $4 / 8 / 2015$

Endereço do autor:

Fábio Cruz<fabiosouzadacruz@gmail.com>

Universidade Federal de Pelotas, Centro de Letras e Comunicação.

Rua Gomes Carneiro, 1 - Centro

96010610 - Pelotas, RS - Brasil 